\title{
Systems Thinking Evidence From Colleges Of Business And Their Universities
}

John H. Seiler, Rutgers University Mini-MBA Program, USA Michelle Kowalsky, William Paterson University, USA

\begin{abstract}
This study investigated instances of the term "systems thinking" among the websites of the Top 25 business schools as ranked by U. S. News and World Report in 2010. Since a greater number of instances of the term and its variants in a university's web documents may indicate an increased interest of the institution in the concept of systems thinking, the universities in this study were rated according to their decreasing instances, counts, or website "hits." Results indicated that while many schools had little to no mention of the term in any form, some schools used it prolifically on their websites, even when searching and hit counting was adjusted to remove duplicates and isolate inaccurate results. Nevertheless, appearance and discussion of the term was limited in official university information displayed by most schools. The authors assert that an increasing importance should be placed on teaching systems thinking at the graduate level and on providing evidence of this work to prospective business students and their prospective employers through university and business school websites.
\end{abstract}

Keywords: System theory; Critical thinking; Business schools; Professional and management development training; Web analytics

\section{INTRODUCTION: SYSTEMS THINKING PIONEERS}<smiles>c1ccccc1</smiles>

ystems thinking is quietly becoming the predominant strategy of choice for those business tacticians who currently dominate their trade. With the recent economic downturn of 2008, the business world more than ever needs to employ leaders who have the ability to see their companies and industries as living organisms. Those individuals, who today can view issues of concern as part of a larger community of consequences, are more likely to be better prepared for the turbulence of tomorrow. As cutting-edge as systems thinking may sometimes seem, the foundation for such knowledge has grown out of over 50 years of university research. These trailblazers have brought systems thinking out of the early stages of human biology and transposed some of their core principles into the fields of business, sociology, management, government and technology.

The term "system dynamics" was coined by MIT engineer Jay Forrester in the 1960s to describe his use of computer-based programming. Forrester pioneered the use of computer simulation testing to observe a system's changes (over a period of time) when presented with variable stimuli. The vast amount of conclusions stemming from these trials helped lead Forrester to predict certain probabilities. The results of these computer simulations revealed the true nature of a system when it interacted with other systems and applications. Many of his works are considered foundational works for any venture into system dynamics modeling.

Barry Richmond was one of Forrester's students who continued his work into systems dynamics with the emerging Apple Macintosh computer in the mid-1980s. Richmond's work entailed designing software for Apple to improve thinking, communication and learning. He authored the user guides on STELLA and IThink software, which helped bridge the gap between technical vernacular and everyday usability for the modern manager. Richmond (1990) insisted anyone could take advantage of system dynamics modeling tools in their own fields if they followed three key fundamentals of building, simulating and communicating. 
Implementing system dynamics in specific disciplines grew monumentally under John Sterman (2000) at MIT. Sterman formulated what he called "management flight simulators" to help business leaders practice scenarios in safe environments. The simulator program was regarded as groundbreaking in systems thinking arenas since it manifests "space and time in a compressed and slowed" setting. Sternman, a Business School professor, created this program so focus could be directed on the tools needed for learning, decision-making and strategy. Sterman's work at MIT with business dynamics has been described as "comprehensive" and "current state-of-the-art" systems thinking (Sherwood, 2002, p. 334). Beyond system dynamics, open systems theory also helped mold current elements of systems thinking culture.

Ludwig von Bertalanffy's work at the University of Vienna in the years before and after World War II helped spawn what is known today as open systems theory. His research in the natural sciences of chemistry and physics led to more questions that answers he surmised. von Bertalanffy (1976) found that while the laws of thermodynamics (the relationship between heat and energy) worked well in explaining the closed systems of classical chemical matrixes, its shortcomings would be revealed when applying such truths to biological studies. Living organisms and their environments, he explained, in fact do not operate in mutually exclusive systems. While these systems can be deemed independent for identification purposes, they truly exist in an open system where their energies are connected intimately. von Bertalanffy scribed that although many questions remain pertaining to systems' relationships, systems theory itself is undoubtedly a foundational component of many interdisciplinary sciences.

The field of open systems theory became more refined under the work of Australian Fred Emery in the 1960s. Emery (1981) took a social science approach to open systems by concentrating on the particular relationships between an environment and an organization. For example, his socio-ecological work paid particular attention to organizations' relationships to a specific environment vis-à-vis its relationship with another organization -- all three linked systems simultaneously being open. Emery concluded that these linkages presented themselves in four "ideal" manifestations. They are as follows: the first being organization to environment, the second being environment to organization and the third being environment to environment. The fourth linkage is thought to be the existence of a "turbulent" environment. Here, the interactions and interdependencies of the open system (between the organization and the environment) are thought to be so complex and amplified that forecasting the consequences are as Emery put it, "totally unpredictable." The research Emery conducted, and later research with his wife, revealed the density of open systems thinking involved in modern social science. The approaches of the pioneers discussed above have included very scientific and theoretical research. Truly understanding the value of systems thinking in today's business milieu does require review the work of both Beer and Checkland as well.

Management Cybernetics is Stafford Beer's theory for studying an organization's effectiveness and efficiency. Cybernetics studies not only what the functions of a system are, but how they react in conjunction with other functions and how that reaction can be defined. In the 1970s, Beer was confident that combining cybernetics with real-world business operations would produce a series of reliable behaviors discernable as either efficiency or waste. His mock-up for facilitating this cybernetic study was through a diagram he called the Viable System Model. Beer's (1979) model took a specific system and tested it against a series of scenarios to determine if success could be predicted. The VSM broke a system down into five individual subsystems to help illustrate the processes of the entire organization. The five are as follows: System 1 - primary activity, System 2 - regulation and planning, System 3 - operations and control, System 4 - development, research and marketing, and System 5 - policy decisions and balance to maintain. Beer explained that, like the functional properties of the brain in the human body, the Viable System Model has the ability to diagnose problems early on, ameliorate issues, proactively adapt and then move on without inhibiting productivity or performance.

Peter Checkland's soft system approach grew out of his frustrations using Systems Engineering methodologies at University of Lancaster in the 1970s. Checkland's (1999) research yielded that those issues he could mend through technological systems thinking methods could not be duplicated with issues of management and business. To this skilled scientist, it appeared now obvious that one type of solution would not be applicable to a different sort of problem. The question he posed was -- why? Checkland and his team found that the way individuals or organizations define problems is nonlinear. What one person sees as a quandary or concern may not even be uniform across all the people in one board room. A soft system inquiry not only looks at why an issue is a 
problem -- but at the reasons we feel it is a predicament from our perspective. Once we can determine these "biases," the bias itself becomes information. Instantaneously, Checkland declares, this information turns into knowledge. Similarities and consensus can finally emerge once an organization moves through this soft systems process with congruence. These types of soft system examinations open the doors of provocative thought when stumbling blocks to progress arise.

\section{THE IMPORTANCE OF SYSTEMS THINKING FOR BUSINESS SCHOOLS}

The path to success has never been guided by a yellow brick road. There has never been a warranty on the back of a diploma that states you have a money-back guarantee for success. And what happens when you actually are the early-bird -- but there still aren't any worms to catch? These metaphors proclaim the real life struggles of every business school student today. The uncertainty of a limp economy only promises hardship to those who are unprepared. But if a student is unprepared -- do they even know it? Do their faculty, without or beyond the ubiquitous alumni or employer survey mandated by accreditation? The MBA-ers of the modern business scene have the unheralded task of not only being successful, but being aware of the fact that "the major social issues of today in which companies play a role demand a richer concept of responsibility” (Wempe, 2009, p. 752).

In business, as many clichés would indicate, knowing is half the battle. Having the ability to identify a valid system of your organization (with its boundaries \& levels), will allow the process of exposing its integral relationships and variables. Making distinctions such as these possibly will, as Kast \& Rosenzweig put it, "prevent confusing conceptual ambiguity" (p. 463). The application of these principles to real-world situations appears daunting at first. Systems thinking is not, by nature, our first choice; humans want to find the easiest solution, implement it and move on. This is where business schools can become highly effective. Not unlike riding a bicycle, once you have learned how to do it, systems thinking can become second nature. In business, involuntary systems thinking will "facilitate more thorough understanding of complex situations and increase the likelihood of appropriate action" (Kast \& Rosenzweig, 1972, p. 462). Obtaining the ability to think systematically provides the user with a vital tool -- the usability of business intelligence.

Today's business schools pride themselves on preparing their students for the world of tomorrow. Graduates with a degree from a highly touted business school will likely leave the classroom feeling they are ready to take the brunt of whatever their careers will throw at them. To use a baseball analogy, recent attempts at graduate business education would yield many students who are catchers behind home plate. They protect the plate as if it represents the bottom line of their company's quarterly statement. It would appear as though internalized systems thinking could help reverse this feeling, thus putting the student in the position of the pitcher who is controlling the action. The feeling of control may be designated business intelligence. Systems theories allow business intelligence to decode the business environment. Jerry Kurtyka (2005) evaluates that "business intelligence helps users to understand their environment in terms that are meaningful, such as key performance indicators and dashboards, and facilitates predicting and controlling the business" (p. 30). Immediately, a systems approach vaults a business intelligence user to a level beyond most others due to the simple level of control they now have over their environment.

Business intelligence, when obtained via systems thinking, can open the door to effectively managing complex issues. A graduate's ability to tame the turbulent waves of business seas not only speaks to his/her ability to evaluate current situations, but preparedness for the future endeavors. Jerry Kurtyka (2002) writes that this type of intelligence is "an instance of the Law of Requisite Variety which states that the degree of complexity in a controller must match the level of complexity in the environment in order for the controller to manage the environment" (p. 32). Managing an environment presents a variety of thorny issues on its own. Dennis Sherwood (2002) explains that at the core of systems thinking there is a supreme responsibility to recognizing "cause \& effect" between "the whole versus the parts" (p. 17). These types of management skills (with a macro \& micro systems perspective) need to be ingrained at the learning level of the business school education. Attention needs to be paid to converting this approach early in the MBA process from simply reactionary to proactively applicatory. Elizabeth $\mathrm{K}$. Thurston (2000) states this type of management education need to be placed in "not only the process that selects and keeps relevant information active in a student's mind but also the mechanism that translates the information learned by the student from short-term memory to long-term memory for storage in the student's mental models" (p. 
14). Long-term storage of systems theory methodology requires basic understanding of both "conceptual 'know what" and "operational "know how" before further development can take place (p. 14).

The mark of any well-regarded manager is one who has the ability to galvanize his/her employees to "buyin" to the company's message. System thinking allows business leaders to monitor the entire organization for strengths and weaknesses, as well as examine their employees for their strengths and weaknesses. Amy J. Walbert (2009) insists "business leaders using systems theory also adopt system analysis methods to identify areas of organizational opportunities and improvements" (p. 18). Business schools may need to take more time teaching students how to communicate with their employees as much as they promote overall company success. Systems theory is not a secret of higher level executives or a code used only by those who sign checks. Business schools from the start need to preach systems thinking across the entire bandwidth of employees. Students must learn to spread their knowledge once they move to supervisory positions. If an organization is going to make a commitment to systems modeling, its success rate increases exponentially with more employees dedicated. As Walbert explains,

"All employees need to be included in he change process; otherwise, change will be difficult. Although some users of the systems approach may not be decision makers, all must be reassured that the change benefits each individual" (Walbert, 2009, p. 19).

So began this investigation of the prevalence of systems thinking in MBA programs across the country -was it being taught, and if so, where? Which universities espoused the concept and how broadly? And how could we determine this? At many universities, a single researcher is the impetus for study of a particular concept or idea, especially at its inception. However, as previously established in this paper, the idea of systems thinking in many of its forms is at least forty years old. This has left plenty of time for institutions to determine if indeed it is a valid concept, whether it can be taught, and how it might become a best practice in the field. Assumptions here are many -- that a mention of systems by a university indicates agreement of the concept's worth; that actual practice in teaching and learning is fully displayed on an institution's web pages; and that current searching mechanisms capture a majority of content at a particular domain.

\section{RESULTS AND DISCUSSION}

In order to determine which business schools and their universities best espoused these views of the importance of systems thinking from any philosophy, view, or vantage point, a review of their websites was performed. During October, 2010, the researchers retrieved the U.S. News \& World Report's Top 25 Business School rankings (full-time MBA schools) for 2010, and visited all 25 schools' university websites and business school websites separately. Once the appropriate "search" box was found (and discovered to be mostly powered by Google $\left.{ }^{\mathrm{TM}}\right)$, the researchers entered the phrase "systems thinking" twice, once as a simple text search and a second time as a phrase within quotation marks. The results of all searches were tallied; several duplicate searches were performed for reliability purposes. Each school in Table 1 is listed in the same order as their rank in the U.S. News \& World Report Top 25. Alongside the name of the school is a column for the results of the business school website search (thus, the count of websites returned, or "hits"), and a similar column for the results from university-wide website searches. Details of the exact nature of the analysis strategy will be described and demonstrated in detail at the conference presentation of this paper. A discussion of these findings appears below.

\section{Business School Websites}

Our search discovered the business school with the most hits for our keywords was the University of California at Berkley's Haas School of Business with 544. There were 6 business schools whose results for this same search found 0 hits. These 6 included: The Olin School of Business at the University of Washington in St. Louis, Tuck School of Business at Dartmouth College, Duke University's Fuqua School of Business, Mays School of Business at Texas A\&M University, Yale Business School and Wharton School of Business at the University of Pennsylvania. All 6 of these schools did not record a single hit for the "systems thinking" search, although potentially the limitations of this method could suggest other ways of determining whether the topic is indeed discussed in these programs. The mode, or number of results which appeared most often, was 0 hits, which is distressing. And the median score result (which appeared in school \#13 of 25 total schools) was 3 hits. 
An interesting set of numbers appear when we remove the 6 business schools that yielded no results in our search. The remaining 19 schools were reexamined and the new low score now moved from 0 to 1 . The only school that recorded 1 hit was the University of Chicago's Booth School of Business. The new average (mean) has now jumped from 43.2 to 56.8. The difference here is 13.6 hits per school. The new business school median (\#10 of 19 schools) is 7 hits and the new mode is tied at 2 and 3 hits. Removing those 6 schools with no findings slightly changes the tallies of our basic statistical measures. A quick glance at our chart finds that only 2 schools found "systems thinking" results in triple digits. Besides UC Berkley's Haas School of Business, the Tepper School of Business at Carnegie Mellon University was the only triple digit institution with 313 hits.

\section{University Websites}

When applying the same search criteria to the university pages of the Top 25 schools, a different set of results is encountered. The school with the highest number of hits was the University of Michigan with 2720 hits. The University of Notre Dame registered with the lowest set of results with 24, making the range of hits from 24 to 2720. The median score here is thus 82 hits, with two modes of 42 and 48 hits respectively. Only one other school along with Michigan hit quadruple digits in the "systems thinking" search, Massachusetts Institute of Technology with 1170 results. Five other schools were found to have at least 100 entries. In no particular order these schools included: Harvard University, Carnegie Mellon University, University of North Carolina at Chapel Hill, Cornell University, and University of Pennsylvania.

Table 1

Counts of Website Results for Searches of "Systems Thinking" during October, 2010, and their Corresponding Ratings from Most to Least Among the 2010 Top 25 Business Schools

\begin{tabular}{|c|c|c|c|c|c|}
\hline $\begin{array}{c}\text { University Name (from U.S. News \& WR Top } 25 \text { of } \\
2010)\end{array}$ & $\begin{array}{c}\text { Business } \\
\text { School } \\
\text { Results }\end{array}$ & $\begin{array}{l}\text { University } \\
\text { Results }\end{array}$ & $\begin{array}{c}\text { Business } \\
\text { School } \\
\text { Rating }\end{array}$ & $\begin{array}{l}\text { University } \\
\text { Rating }\end{array}$ & $\begin{array}{l}\text { Combined } \\
\text { Rating }\end{array}$ \\
\hline Harvard University, Boston, MA & 32 & 277 & 5 & 4 & 9 \\
\hline Stanford University, Stanford, CA & 7 & 42 & 9 & 21 & 30 \\
\hline $\begin{array}{l}\begin{array}{l}\text { Massachusetts Institute of } \\
\text { Cambridge, MA }\end{array} \\
\text { Technology }\end{array}$ & 53 & 1170 & 3 & 2 & 5 \\
\hline Northwestern University (Kellogg), Evanston, IL & 3 & 95 & 12 & 10 & 22 \\
\hline University of Pennsylvania (Wharton) Philadelphia, PA & 0 & 228 & 15 & 5 & 20 \\
\hline University of Chicago (Booth), Chicago, IL & 1 & 46 & 14 & 19 & 33 \\
\hline University of California at Berkeley (Haas), CA & 544 & 94 & 1 & 11 & 12 \\
\hline Dartmouth College (Tuck) Hanover, NH & 0 & 49 & 15 & 17 & 32 \\
\hline Columbia University, New York, NY & 4 & 42 & 11 & 21 & 32 \\
\hline New York University (Stern), NY & 5 & 40 & 10 & 22 & 32 \\
\hline Yale University, New Haven, CT & 0 & 88 & 15 & 12 & 27 \\
\hline University of Michigan at Ann Arbor (Ross), MI & 20 & 2720 & 6 & 1 & 7 \\
\hline University of Virginia (Darden) Charlottesville, VA & 17 & 54 & 7 & 16 & 23 \\
\hline Duke University (Fuqua), Durham, NC & 0 & 68 & 15 & 15 & 30 \\
\hline $\begin{array}{l}\text { University of California at Los Angeles (Anderson), } \\
\text { CA }\end{array}$ & 3 & 48 & 12 & 18 & 30 \\
\hline Carnegie Mellon University (Tepper), Pittsburgh, PA & 313 & 166 & 2 & 6 & 8 \\
\hline University of Texas at Austin (McCombs), TX & 20 & 98 & 6 & 8 & 14 \\
\hline Cornell University (Johnson) Ithaca, NY & 2 & 501 & 13 & 3 & 16 \\
\hline Washington University in St. Louis (Olin), MO & 0 & 44 & 15 & 20 & 35 \\
\hline $\begin{array}{l}\text { University of North Carolina at Chapel Hill (Kenan- } \\
\text { Flagler), NC }\end{array}$ & 12 & 124 & 8 & 7 & 15 \\
\hline $\begin{array}{l}\text { University of Southern California (Marshall), Los } \\
\text { Angeles, CA }\end{array}$ & 3 & 48 & 12 & 18 & 30 \\
\hline University of Indiana at Bloomington, IN & 2 & 82 & 13 & 13 & 26 \\
\hline Texas A\&M (Mays), College Station, TX & 0 & 76 & 15 & 14 & 29 \\
\hline University of Maryland at College Park (Smith), MD & 37 & 96 & 4 & 9 & 13 \\
\hline University of Notre Dame (Mendoza), IN & 2 & 24 & 13 & 23 & 36 \\
\hline
\end{tabular}


Table 1 documents the number of hits for each business school website and each university website from the Top 25 schools. When assigning a rating to each based on the number of results, the business school website with the most hits is UC Berkeley (Haas), which is thus assigned a rating of 1 . Likewise, each successive count was rated 2, 3, etc., and includes the 6 schools with 0 hits at the lowest ratings, respectively. When assigning a rating to each based on an examination of university-wide results of the searches, the website with the most hits is Michigan, which is again assigned a rating of 1 . This research discloses that when simply adding the ratings of the business school and university websites together to provide a combined impact, the highest-positioned school is MIT. Perhaps this is due to an increased emphasis on the job roles in physics and the like which specifically utilize this type of process, which may or may not be a limitation. Yet, this school was rated 3rd on our business school chart and $2^{\text {nd }}$ on our university chart. The lowest rated of our top 25 was Notre Dame. The Irish appeared $13^{\text {th }}$ on our business school chart and $23^{\text {rd }}$ on our university chart. Even with these combined ratings, the school with the overall highest amount of combined hits was not MIT, but Michigan with 2740. The University of Michigan ranked $6^{\text {th }}$ in our business chart and $1^{\text {st }}$ in our university chart. Michigan's large amount of university hits (2720) may be an anomaly amongst the top 25 schools in our group, yet its high results yielded more hits than any other business \& university website combined, and via the same back-end search mechanism.

\section{CONCLUSION}

University websites are not only a marketing tool to prospective students, prospective university faculty, and prospective employers of graduates. They are also a record of the intellectual conversation at an institution as it is recorded in university documents, news, and statements of interest. If indeed systems thinking, system dynamics, and similar concepts are being taught, discussed, or pondered at the university level, this information needs to shine through their university or business school web presence, lest viewers of online university materials assume these topics are not of interest.

Playing by the rules, being financially stout, and serving the social conscience is already a long laundry list of requirements for any student to undertake while attempting to earn a business degree. The university or college chosen can make a significant impact in preparing a person for the field on which they wish to embark. Now, the "bottom line" of any financial statement is crucial to a business's success; there is no doubt about it. Many struggling enterprises, more specifically their executives, are working in a backwards manner, though -- operating with too much perspective from the bottom line looking up. The change in thinking now needs to shift at the business school level. Business schools, whether large or small, would do well to adopt a systems thinking approach to their entire MBA curriculum. A systems thinker in a business setting allows themselves to view their role as not only being a decision-maker, but as a facilitator, analyst, evaluator and scientist simultaneously. As the world becomes more competitively crowded, modern success demands that business schools provide systems thinking education to students who intend to nurture and maintain the health of their future organizations.

Integrating systems theories into curricula that have had decades of blossoming success is surely no easy task. Not only is the topic of systems theory difficult to implement, it is even more difficult to teach. As Kast and Rosenzweig (1972) wrote, "While proclaiming a broad systems viewpoint, we often dismiss variables outside our interest or competence as being irrelevant, and we only open our system to those inputs which we can handle with our disciplinary bag of tools" (p. 464). A core value of systems thinking understands that what we see is not the only part of the equation. In fact, the spine of any organization would point to the relationships within the system as actually defining what makes or breaks success. This is inherently difficult, though. Kast \& Rosenzweig deduce that "perhaps it is because we know a great deal more about the elements or subsystems of an organization than we do about the interrelationships and interactions between these subsystems" (p. 448). Nevertheless, integration of systems thinking with the fabric of a graduate business program, or at the very least its online documentation, should be not only of concern to faculty but to institutional development as well.

Previously, our colleagues may have agreed that part of the responsibility for business education lies with the individual employee and his or her orientation to a new role, and part of the responsibility lies with the employer to nurture and manage talent, and yet another part of the responsibility lies with the degree-granting institution to ensure that workers and managers are prepared for what they are undertaking. However, in employing a systems model to evaluate this very topic, it becomes clear that many parts of the system are involved in determining a 
university's web presence, curricula, trajectory, and the like. Further study is planned by the researchers to determine and categorize the contexts in which the term is used by these universities and their business schools, and to determine evidence of unique uses of the term and its variants by multiple campus groups.

\section{AUTHOR INFORMATION}

John H. Seiler is a Business Analyst \& Performance Coordinator for The New York Times. He is a graduate of Rutgers University's Mini-MBA Program as well as their Lean \& Six Sigma Green Belt Training co-hosted by Lockheed Martin. He earned his undergraduate degree in Interpersonal Communication at Villanova University, along with minors in English and Arab \& Islamic Studies. He is an active professional member of the Future Business Leaders of America, Phi Beta Lambda Chapter, and serves as an FBLA national competition judge.

Michelle Kowalsky is an Assistant Professor and Program Coordinator at William Paterson University. She teaches systems thinking to graduate students in the College of Education, and serves as a Masters Thesis Advisor. She holds a doctorate from Pepperdine University, and is active in the American Educational Research Association and the American Library Association. Her research focuses on the development of complex information, communication, and thinking skills via technology.

\section{REFERENCES}

1. $\quad$ Beer, S. (1979). The heart of the enterprise. London: Wiley.

2. $\quad$ Checkland, P. (1999). Systems thinking, systems practice $\left(2^{\text {nd }}\right.$ ed.). London: Wiley.

3. $\quad$ Emery, F. (1981). Open systems thinking (Volumes I \& II). New York: Penguin.

4. $\quad$ Forrester, J. (1961). Industrial dynamics. Cambridge, MA: MIT Press.

5. Kast, F. E., \& Rosenzweig, J. E. (1972). General system theory: Applications for organization and management. Academy of Management Journal, 15(4), 447-465.

6. $\quad$ Kurtyka, J. (2005). A systems theory of business intelligence. DM Review, 15(12), 30-33.

7. Richmond, B. (1990). Systems thinking: A critical set of critical thinking skills for the 90's and beyond. In D. F. Anderson, G. P. Richardson, \& J. D. Sterman (Eds.), System Dynamics 1990, (pp. 934-947). Chestnut Hill, MA: System Dynamics Society.

8. Sherwood, D. (2002). Seeing the forest for the trees: A Manager's guide to applying systems thinking. London: Nicholas Brealey Publishing.

9. Sternman, J. (2000). Business dynamics: Systems thinking and modeling for a complex world. Boston: McGraw Hill.

10. Thurston, E. K. (2000). Enabling systems thinking in the "Mesonic Millennium": The need for systemic methodologies for conceptual learning in undergraduate management education. Journal of Management Education, 24: 10-31.

11. U. S. News \& World Report (2010). "Rankings: Best Business Schools [Graduate Schools]." Retrieved October 21, 2010, from http://grad-schools.usnews. rankingsandreviews.com/best-graduate-schools/topbusiness-schools/rankings

12. von Bertalanffy, L. (1976). General system theory: Foundations, development, applications (Revised ed.). New York: George Brazilier.

13. Walbert, A. J. (2009). Minding analysis, improvement and quality. Industrial Management, 51(2), 16-19.

14. Wempe, J. (2009). Industry and chain responsibilities and integrative social contracts theory. Journal of Business Ethics, 88, 751-764. 
NOTES 